There was also considerable discussion respecting the recommendation by a committee of the American association for the advancement of science of the word "alumin $u m$ " for the name of the metal, Prof. Houston speaking strongly in favor of the retention of the name "aluminizm," as being more in harmony with the nomenclature of the other metals, calcium, indium, magnesium, potassium, etc.

The meeting then adjourned.

L. F. RONDINELLA,

Secretary.

\title{
A NOTE ON SOME DANGERS IN ELECTRIC LIGHTING.
}

By WM. McDevitT.

Inspector of the Philadelphia Board of Fire Underwriters.

[Read at the stated meeting of the Electrical Section, held February 24, 1801.]

After several years of experience in noting the dangers occurring in the use of electric lighting, it has been clearly demonstrated that in nearly every case the accidents resulted through ignorance both on the part of the workmen engaged in installing the wires and the lessee to whose care the new apparatus was entrusted.

These practical illustrations served as valuable lessons to those who witnessed them, more especially to the work. men, whose education in the business consisted merely in following plans laid out by the contractor.

Although the introduction of electric lighting has rapidly increased in our city, its use has been comparatively free from accidents, proving that most of the inherent dangers have been controlled, leaving but few features that require the attention of inventive minds to overcome. The most important of the existing defects is that relating to fusible connections, as the innumerable variety of alloys used for fuse metal is very misleading and is still an element of danger. Some of these compositions possess the properties of good electrical conductivity and are slow to heat; other compositions are of a character exhibiting weakness when heated, resulting in annoyance from continuous breaks and offering temptations (as has been found) to use ordinary wire in the absence of proper fuses. 
Another universal danger in elcetric lighting results from the want of some uniform or more ready method of perfecting splices or joints in conductors. Some workmen are in the habit of making loose copper unions, leaving the solidity of the joint dependent on solder, which, being a metallic cement, is liable to be fused by a possible heavy short-circuit occurring on the linc, thus melting the solder and leaving a loose conncetion.

Probably the most alarming danger exists through the possibility of lightning being conducted into houses lighted by electricity where the latter is supplied by aërial wires. The existence of this danger has been demonstrated where the house wires are attached to gas fixtures, offering a ready path for the lightning, which, in leaping from the charged wires to the gas pipes, carries the electric light current across, forming an arc, which pierces the pipe, and where gas is prescnt, it will be ignited, causing a steady blaze. If this accident should occur near the ceiling, the building would be endangered.

With the rapid introduction of new appliances in electrical seicnce, it may reasonably be expected that the defects above-mentioned will be overcome in the near future.

\section{A NEW ACCUMULATOR PIATE.}

IBY C. W. P'IKE,

Instructor in Electrical Engineering, University of P'ennsylvania.

[Read at the stated meeting of the Electrical Section, January 24, 1801.]

While in Lowell, Mass., last year, a temporary craze upon the subject of storage batteries took almost complete possession of the town. The result of this was the production of several so-called new storage batteries. In reality, there was no attempt to produce a new type of accumulator, either by making use of new solutions or new metals. The sole novelty was in the form of the plates.

The inventors had but one object in view, namely, to canstruct a plate of such form that the active material would voi. cXXXI. 